\title{
SOSTENIBILIDAD Y RESIDUOS SÓLIDOS URBANOS. ANÁLISIS COMPARADO DE LOS DISTINTOS MODELOS DE TRATAMIENTO PARA GUIPÚZCOA (COMUNIDAD AUTÓNOMA VASCA)
}

\author{
Pedro José Lozano Valencia ${ }^{1}$ \\ Itxaro Latasa Zaballos ${ }^{1}$ \\ Gorka Bueno Mendieta ${ }^{2}$ \\ 'Departamento de Geografia, Prehistoria y Arqueología de la Universidad del País Vasco UPVIEHU \\ ${ }^{2}$ Departamento de Tecnología Electrónica de la Universidad del País Vasco UPVIEHU \\ pedrojose.lozano@ehu.es, itxaro.latasa@ehu.es, gorka.bueno@ehu.es
}

\section{RESUMEN}

Este artículo resume un trabajo de análisis e investigación realizado en torno a un problema tan importante y relacionado con la sostenibilidad como el modelo de recogida y tratamiento de los residuos sólidos urbanos. En él se muestran los resultados de la aplicación de un análisis comparado a dos planificaciones sectoriales que sobre los residuos sólidos urbanos se han presentado en los últimos 10 años para la provincia de Guipúzcoa. De los dos modelos, el que apuesta por una recogida a ultranza de las dos fracciones y, sobre todo, de una recogida selectiva de la materia orgánica, muestra un mayor grado de eficacia y eficiencia que el que apuesta por una recogida en masa y el tratamiento con incineradora al final del proceso.

Palabras clave: Residuos sólidos urbanos, sostenibilidad, Guipúzcoa, planificación sectorial, análisis del ciclo de vida.

\section{ABSTRACT}

This paper summarizes a analysis and research work of a really important problem related with the sustainability of collection model and treatment of Urban Solid Waste Manage-

Fecha de recepción: febrero 2015.

Fecha de aceptación: diciembre 2015. 
ment. The paper shows the results of the application of comparative analysis between two sector planning about Municipal Solid Waste that have been presented in the past 10 years for the province of Guipúzcoa. One of two models, which is the one that promotes a full selective collection and especially the selective collection of the organic fraction of urban waste, shows a greater degree of effectiveness and efficiency than the one promoting the incineration at the end of the process.

Keywords: Solid urban waste, sustainability, Guipuzcoa, sectorial planning, life cycle analysis.

\section{INTRODUCCIÓN}

La sostenibilidad se ha convertido en el núcleo del discurso en torno a la gestión de residuos y es el principio sobre el que se ha construido el nuevo modelo de gestión de los residuos de la Unión Europea (Koroneos y Nanaki, 2012). La elección de un sistema de gestión de residuos urbanos ha sido y es una cuestión muy conflictiva y debatida que ha generado una abundante literatura destinada a ayudar a los decisores técnicos y políticos a elegir la mejor alternativa. Sin embargo, en 2008 la aprobación de la nueva directiva de residuos de la UE elevó a la categoría de norma un conjunto de principios y un modelo de gestión de los residuos sólidos urbanos largamente anunciado. La nueva jerarquía de residuos, que situaba la prevención, la preparación para la reutilización y el reciclaje junto con el compostaje y la biogasificación por delante de los procedimientos de incineración con recuperación energética zanjaba aspectos esenciales del debate y debería haber supuesto el punto de partida de una adaptación de las políticas y planes de residuos en la Unión Europea. Incomprensiblemente, el debate continua y desde algunos sectores se sigue demandando la incineración como tratamiento prioritario para los residuos urbanos.

En los últimos años ha existido una creciente preocupación, dentro del Territorio Histórico de Guipúzcoa (THG), Comunidad Autónoma del País Vasco (CAPV), acerca de una materia tan extraordinariamente compleja y controvertida como son los residuos, su recogida, tratamiento, modelo integral de gestión, etc. Ya a finales de la década de los 70 del siglo XX los ayuntamientos fueron configurando mancomunidades para hacer frente, de una manera colegiada y atendiendo a la economía de escalas, a distintos problemas o servicios de carácter general (Lozano y Lozano, 2008).

Diferentes problemas, unidos a la rápida colmatación de los distintos vertederos y al endurecimiento de la legislación que en esta materia emanaba de la Unión Europea (UE), dio como resultado que a finales de los 90 y principios del nuevo siglo comenzara un rosario de nuevas planificaciones por mancomunidades confluyendo en el Plan Integral de Residuos de Guipuzcoa (PIGRUG) que vio la luz el 17 de diciembre de 2002 y que planteaba el tratamiento integral de los residuos sólidos urbanos (RSU) del mencionado territorio histórico con un año horizonte centrado en 2016. Este año meta se considera, no obstante, como excesivamente alejado puesto que ya en 2008 la propia Diputación Foral de Guipúzcoa (DFG) promovió y aprobó un nuevo documento. Las razones de la redacción y presentación de ese éste se deben buscar en la existencia de un marco regulatorio y normativo que abogaba por 
nuevos objetivos de prevención, reducción, reutilización, reciclaje y compostaje a escala europea, a partir de la nueva directiva que en materia de residuos fue publicada este mismo año (Directiva 2008/98 CEE), por lo desacertado de la prognosis elaborada por el viejo plan en cuanto al crecimiento esperado de la producción de residuos y otros parámetros relacionados con la caracterización de los mismos y por la profundización de las distintas alternativas de recogidas selectivas, fundamentalmente de la fracción orgánica (FO). Por ello, mediante la Norma Foral 7/2008, de 23 de diciembre, publicada en el Boletín Oficial de Guipúzcoa $\mathrm{n}^{\mathrm{o}} 250$, las Juntas Generales de dicho territorio aprobaron el Documento de Progreso (20082016) (DdP). A efectos de integrar toda la planificación en un único documento procede la incorporación del citado PIGRUG como anexo del DdP, de manera que aquél conserva su vigencia en los aspectos que éste no ha contemplado. En cualquier caso, todo este proceso planificador, amén de respetar en mayor o menor grado la prelación establecida por la directiva europea de residuos (DR), abogaba por una solución final para todos aquellos no reutilizables o reciclables que apostaba por su eliminación y aprovechamiento energético a partir de una incineradora de RSU.

Asimismo, la planificación sectorial definida en la mencionada norma foral queda completada con el Plan Territorial Sectorial de Infraestructuras de Residuos Urbanos de Guipúzcoa, el cual otorga sustento territorial o ubicación a las soluciones de gestión que plantea el DdP, entre otras, la ubicación de la mencionada incineradora. Este es el único PTS que, en materia de residuos y dentro de la CAPV, se encuentra en vigor (Decreto Foral 24/2009, de 21 de Julio, por el que se aprueba definitivamente el Plan Territorial Sectorial de Infraestructuras de Residuos Urbanos de Guipúzcoa).

Por otra parte, ya en 2012 y motivado por un cambio de gobierno en el que la fuerza política con más representantes es contraria a la incineración, la DFG aprueba y publica la Estrategia de Desarrollo del Documento de Progreso (EDDdP) 2008-2016, con unos parámetros y estrategias muy diferentes a las que había venido definiendo tanto el anterior grupo de gobierno, como el resto de figuras de planificación. La EDDdP del PIGRUG, tiene por objeto adaptar el modelo de tratamiento y gestión de RSU propuesto, a los nuevos datos de gestión, a la previsión del incremento de la recogida selectiva, a la normativa y a la legislación vigente en la materia. En este caso, además, se desaprueba y suprime la mayor infraestructura planificada y no construida para la eliminación de los residuos, que era la incineradora, mientras se apuesta por una recogida selectiva mucho más intensiva y la reducción drástica de todos aquellos residuos que no sean susceptibles de reutilizarse, compostarse, biometanizarse o reciclarse. Con ello, la nueva planificación aboga por unos residuos inertes a los que se les eliminarán, en la mayor proporción posible, todos los elementos susceptibles de ser aprovechados, especialmente la FO. De esta forma, además, pueden ser embalados y depositados en depósitos controlados dentro de territorios o sectores ya impactados paisajísticamente como canteras.

Toda esta profusión de documentos, autodefinidos como sostenibles y la existencia de posturas políticas, sociales y mediáticas muy contrapuestas, ha dado lugar a un encendido debate social en el que, muchas veces, se toman posturas poco veraces o se alimentan mitos que no responden estrictamente al necesario rigor y análisis objetivo. En este sentido, el presente artículo recoge de manera sucinta los resultados de la mencionada investigación reali- 
zada por un equipo transdisciplinar, cuyo objetivo general es arrojar luz y efectuar un análisis exhaustivo y riguroso sobre las diferentes metodologías, tratamientos y planificaciones.

\section{OBJETIVOS}

Partiendo del fin general que persigue el análisis comparado del grado de sostenibilidad de los dos grandes métodos de tratamientos de residuos sólidos urbanos para Guipuzcoa, a continuación se exponen los objetivos operativos, secundarios o metodológicos:

- Realizar una compilación lo más exhaustiva posible sobre la información acerca de los métodos contrapuestos.

- Realizar una comparación sectorial de los dos grandes métodos de tratamientos de residuos propuestos para Guipúzcoa, teniendo en cuenta los siguientes vectores: repercusiones técnicas, ambientales y de salud, socioeconómicas y jurídico-administrativas.

- Completar un capítulo final de resultados y conclusiones donde, de forma sintética y general, se expongan los pros y contras de cada una de las dos metodologías propuestas y analizadas.

- Arrojar luz sobre las informaciones que desde distintos ámbitos (político, mediático, social y técnico) se están dando con respecto a las dos diferentes políticas referenciadas (con una recogida selectiva mucho más desarrollada y sin incineradora y una recogida menos selectiva pero con la incineración al final del ciclo.

- Realizar un análisis pormenorizado acerca de los distintos métodos, iniciativas, corrientes técnicas y ciudadanas que en materia de residuos se están dando en territorios punteros y suficientemente cercanos, fundamentalmente en el contexto de la UE.

\section{METODOLOGÍA}

Para lograr una eficacia en el cumplimiento de los mencionados objetivos, a continuación se expondrán los pasos metodológicos más importantes para la generación del informe y, en definitiva, para la culminación del presente artículo:

- Compilación de los documentos necesarios:

a. Compilación de los documentos de planificación realizados para Guipúzcoa.

b. Compilación de la información que en materia técnica exista, en relación a las dos grandes metodologías de gestión y tratamiento de residuos.

c. Compilación de la información necesaria y de carácter técnico, jurídico, ambiental, de salud y socio-económico que sobre estos métodos existan en otros territorios más o menos cercanos (Europa).

- Análisis de la información compilada en la anterior fase. Análisis sectorial de los siguientes aspectos: análisis técnico y de eficiencia económica; análisis ambiental y de salud; análisis socioeconómico y, por último, análisis jurídico-administrativo.

- Diagnóstico sectorial de cada uno de los aspectos antes contemplados. 
Por otra parte, partiendo de la descrita compleja y discutida realidad, desde la Universidad del País Vasco/Euskal Herriko Unibertsitatea (UPV-EHU) y, teniendo en cuenta el papel que la universidad debe jugar con respecto a la sociedad en la que se inserta: utilidad, reflexión crítica y razonada, ética y generación de argumentos científicos, técnicos y sociales independientes e imparciales, nos propusimos arrojar luz acerca de las dos grandes líneas o metodologías propuestas en el ámbito de la gestión de los residuos.

En la comparación se apuesta por la metodología de Análisis del Ciclo de Vida (ACV) por considerar ésta como la herramienta metodológica más interesante para este tipo de análisis comparativos de realidades complejas. Por otra parte, la Unión Europea la considera como la mejor de las metodologías para abordar cualquier tipo de planificación y organización de la gestión de los residuos (Comisión Europea, 2011). El ACV se configura como una herramienta metodológica que sirve para medir el impacto ambiental de un producto, proceso o sistema a lo largo de todo su ciclo de vida (desde que se obtienen las materias primas hasta su fin de vida). Se basa en la recopilación y análisis de las entradas y salidas del sistema para obtener unos resultados que muestren sus impactos ambientales potenciales, con el objetivo de poder determinar estrategias.

La metodología del análisis del ciclo de vida (ACV) está recogida por las normas UNEEN ISO 14040 y 14044 y es una herramienta fundamental que mediante el estudio de los flujos de materia-energía de un sistema nos permite realizar un adecuado análisis económicoecológico de dicho sistema.

En este estudio se ha realizado la modelización, aplicando la metodología del ACV de dos sistemas diferentes de tratamiento y gestión de residuos para el THG. Por un lado se ha creado el modelo que llamamos EPIGRUG para modelizar el comportamiento del escenario base recogido en el DdP del PIGRUG para el año horizonte 2016, y por otro lado se ha creado el modelo que denominamos ALTERNATIVO para modelizar un escenario que trata de gestionar el mismo flujo de residuos pero sin incineración y con un alto grado de recogida selectiva, igual pero con variantes al EDDdP.

\section{CONTEXTO Y ESTADO DE LA CUESTIÓN}

Existe una gran escasez de muchas de las materias primas procedentes de la corteza terrestre, lo cual lleva a la UE a declarar que estamos en el fin de la era de los recursos baratos $\mathrm{y}$, por tanto, a generar directivas y políticas que coadyuven al máximo aprovechamiento de las materias. Además de la escasez, existen otros factores que agudizan el grado de criticidad de los recursos escasos (Comisión Europea, 2010):

- frecuentemente 2-3 países concentran la mayoría de las reservas, lo cual les permite imponer las condiciones de suministro (Ad-hoc Working Group 2010; Diederen 2010);

el proceso mundial de nacionalización de los recursos determina frecuentemente que los países reduzcan los flujos de exportación para alargar la vida de sus recursos (IMP., 2008);

muchos países exportadores de recursos son políticamente muy inestables. 
Los precios de las materias primas, además de tener una tendencia a elevarse, están sometidos a un nivel muy alto de volatilidad.

La escasez de recursos determina factores de agravamiento de los impactos ambientales en la extracción y transporte de recursos: la baja y decreciente ley de los recursos conlleva explotar yacimientos muy difusos y altamente impactantes; es cada vez más frecuente que la explotación de recursos se realice en zonas de alto valor ecológico o en ecosistemas frágiles (Ártico, zonas abisales, etc.) o situados en zonas de difícil acceso (yacimientos de petróleo o nódulos metálicos situados en las profundidades del océano y la tierra), y no puedan evitar severos e irreparables impactos ambientales; los circuitos de transporte son cada vez más largos, lo que genera grandes impactos ambientales (emisiones a la atmósfera, vertidos al agua, impactos de accidentes).

La UE es la región del mundo con mayor dependencia de recursos. Depende en un 97\% de la importación de minerales metálicos. Este panorama explica la gran preocupación de la UE y del mundo empresarial por lograr un abastecimiento seguro y la multiplicación de iniciativas diplomáticas y de autoabastecimiento por la vía de maximizar la transformación de los residuos en recursos. A la misma vez, se trata de sustituir los recursos no renovables por aquellos que sí lo son, especialmente los relacionados con los recursos energéticos. Por ello impulsa una economía circular de materiales, la cual sólo se puede basar en convertir los residuos en recursos. Ello determina una insistencia apremiante sobre los estados para que apliquen la jerarquía de residuos y que esto se traduzca en la imposición de obligaciones legales cada vez más exigentes. Por un lado, en la dirección de reducir los residuos eliminados y, por otro, en exigencias de maximizar la prevención, reutilización y reciclado de los mismos. Todas estas cuestiones son palpables en el progresivo endurecimiento de las directivas relacionadas con los residuos que desde la UE han sido emanadas en los últimos años, así como los distintos informes y planes relacionados con la sostenibilidad.

Esta política, además de potenciar el autoabastecimiento, provoca la irrupción de nuevas empresas necróforas y descomponedoras y la creación de gran cantidad de puestos de trabajo. Todo ello redunda, además, en una clara reducción de los importantes impactos ambientales que provocan los tratamientos situados más abajo en la jerarquía de residuos (vertido e incineración). A medida que se vayan encareciendo las materias primas, la rentabilidad de aplicación de la jerarquía de residuos se irá incrementando.

Es por ello que la UE viene multiplicando la puesta en práctica de múltiples instrumentos para impulsar una economía circular: de impulso a la prevención (Directiva de ecodiseño, responsabilidad ampliada del productor-RAP); de impulso del reciclado y la reutilización (regulación administrativa: objetivos mínimos que deben alcanzar los Estados, RAP); instrumentos económicos (tasas proporcionales al volumen de residuos generados; impuestos a la incineración y vertido, que tienen en cuenta sus impactos ambientales y en la salud; subvenciones a la reutilización y reciclado). Estos instrumentos económicos están siendo puestos en práctica, sobre todo, por los países líderes. A continuación se dará una explicación más pormenorizada de las líneas maestras de la gestión de residuos según la jerarquía de la UE en dichos países.

Las anteriores consideraciones explican el elevado grado de reciclado y reutilización (7080\%) de seis estados miembros: Alemania, Holanda, Bélgica (con políticas diferenciadas en Valonia y Flandes), Austria, Suecia y Dinamarca (Comisión Europea, 2010). 
En el caso de los RSU y asimilados, estas políticas están dando resultados en línea con la jerarquía de residuos: Por una parte, se está reduciendo el volumen de residuos en la UE, sólo en parte debido a la crisis económica (Diputación Foral de Guipúzcoa, 2008), después de varios años de estancamiento; el vertido está reduciéndose mucho (un 35\% en el periodo 1995-2009); la incineración se está estancando en los últimos años, aunque creció un 56\% en el periodo 1995-2009; el reciclado creció un 159\% y el compostaje un 239\% en el mismo periodo y mantienen una clara progresión, sobre todo en los últimos años. Esto es especialmente reseñable si tenemos en cuenta que dicha tendencia tiene una correlación directa con el estancamiento de los procesos de incineración y vertido.

La experiencia de los estados europeos líderes en la promoción de una economía circular muestra que para lograr ese objetivo se debe impulsar una política que contiene una batería de actuaciones que describiremos de forma general: Impuestos y/o prohibiciones en relación con el vertido y la incineración de residuos. Los resultados de las evaluaciones ambientales de la Unión Europea no dejan lugar a dudas, los porcentajes de vertido e incineración de residuos han disminuido en aquellos países que han aplicado estas políticas.

Los sistemas de pago por generación de residuos han demostrado su eficacia a la hora de evitar la generación de residuos y potenciar la recogida de residuos selectiva (Astrup, 2007). En este sentido, no puede mantenerse por mucho más tiempo el depósito incontrolado y anónimo de los contenedores de calle, tal y como los conocemos hasta ahora. Aplicando el principio general de "el que contamina paga" se debe apostar por un sistema que, como el puerta a puerta $(\mathrm{PaP})$, reduce los residuos, selecciona todas las fracciones y, por tanto, es más sostenible a la vez que equipara los esfuerzos de los ciudadanos y no genera diferencias, como las políticas en torno a la recogida en masa, o incluso el $5^{\circ}$ contenedor para la FO, si no se llega a una recogida selectiva generalizada. Los programas de responsabilidad de los productores han permitido a diversos estados obtener y redistribuir los fondos necesarios para mejorar la recogida selectiva y el reciclado.

Pero tales iniciativas contienen múltiples actuaciones y, además, aparecen otras no contempladas. La más importante no contemplada es la prevención, política que constituye la máxima prioridad para la mayoría de las experiencias reflejadas aquí. Hay que subrayar que la aplicación conjunta integrada de estas actuaciones tiene un gran poder transformador y no así la aplicación sólo de algunas de ellas y no bien integradas.

A continuación se desglosan las actuaciones principales puestas en práctica por los estados anteriormente referenciados indicando el país y el año de inicio de cada actuación.

\section{IV.1. Políticas regulatorias}

En Austria se ha impulsado la recogida selectiva y obligatoria de residuos orgánicos (1995), además de la prohibición de vertido de residuos con un contenido orgánico superior al 5\% (1997). En Alemania, por su parte, existe la obligación de los productores a reciclar el embalaje o envase de sus productos (sistema punto verde desde 1991), la prohibición de vertido de residuos líquidos, residuos infecciosos, residuos explosivos, de que el vertido tenga un máximo de contenido en carbono (FO) del 5\%, etc. (2005) y la recogida selectiva de biorresiduos (1998). En Holanda también existe una combinación de medidas entre las que cabe destacar la prohibición de eliminación en vertederos de RSU, reciclables 
y de construcción (1996) y el decreto de imposición de las condiciones a la incineración más exigentes del mundo. En Suecia, a día de hoy, existe la prohibición efectiva del vertido de materia combustible (2002) y orgánica (2005). Bélgica, por su parte, decidió no abrir nuevos vertederos (1993). Unos años después decidió no aumentar la capacidad de incineración. En la región de Flandes se apostó por medidas sobre vertidos muy restrictivas (2005) y alcanzar para 2010 una recogida selectiva del 75\%, mientras que en Valonia se configuró un calendario paulatino (2004-2010) que obligó progresivamente a reducir las diferentes fracciones a verter.

\section{IV.2. Políticas fiscales}

\section{IV.2.1. Impuestos}

En Austria se están aplicando impuestos a la incineración de 8-9€/t (2006) además de otros que gravan el vertido o la exportación para vertido de 9-30€/t, dependiendo de las condiciones tecnológicas y ambientales del vertedero (2012). En Dinamarca se aplican al vertido y la incineración, de manera que han ido aumentado de 5.3€/t (1987) a 63.3€/t (2010). Holanda, por su parte, aplica estas medidas sobre vertido de $17 € / t$ (materia densa) y de $108 € / t$ (materia ligera) (1996). Sin embargo, estas medidas fueron retiradas en 2012 porque es tan reducido el vertido que no cubre los costes de gestión. Suecia combina dos tipos de medidas, por una parte aplica un impuesto sobre el vertido (2000), que se ha incrementado de 27 a $47 € / t$ y, a la misma vez, aplica otro a la incineración de RSU de 50€/t (2006). También cuenta con un sistema de pagos retornables para botellas de vidrio, latas y botellas de PET. Flandes, por último, aplica tasas variables al vertido (desde 11.64€/t a 79€/t, según materiales) y a la incineración (7.41€/t) (2009).

\section{IV.2.2. Subsidios}

En Austria se están aplicando subsidios a tecnologías innovadoras en recuperación y prevención de residuos (1992). Mientras tanto, Holanda los aplica a técnicas innovadoras de recogida, reutilización y reciclado, y a la estimulación de un mercado de plástico secundario (2002).

\section{IV.2.3. Sistemas de pago en función del peso}

Éstos han sido implementados eficazmente para los residuos domésticos en Holanda. Por su parte, en Flandes casi todos los municipios han establecido sistemas de pago según el volumen de residuos generados (2009).

En muchos casos en Europa, allí donde se aplica el pago por generación, el tipo de recogida aplicado es el sistema de recogida Puerta a Puerta ( $\mathrm{PaP}$ ) (en sus diferentes versiones). Esto es lo que opina la Agencia Medioambiental Europea (2009): “En Italia, los sistemas de recogida selectiva puerta a puerta son los que mejores resultados han dado, tanto a nivel de cantidad como de calidad en la recogida”. 


\section{IV.3. Campañas de comunicación: la importancia de la aceptabilidad pública de las medidas a implementar}

En Holanda se apostó, hace unos años, por desarrollar campañas de comunicación local dirigida a la ciudadanía y un canal de información a las autoridades. En Flandes, por su parte, se implementaron programas de comunicación para modificar los comportamientos de los ciudadanos. Éstos han tenido un papel esencial en los altos niveles de reciclado, de manera que se ha reducido drásticamente los costes de la gestión de RSU y se ha elevado mucho el grado de satisfacción ciudadana por la gestión de residuos.

Por último, las conclusiones de Colomer et al. (2010) al analizar las políticas exitosas de aplicación de la jerarquía de residuos deben ser tenidas en cuenta por los gestores públicos que pretenden avanzar en este sentido: "cuando se han hecho los esfuerzos suficientes, facilitando la información necesaria, estableciendo canales o medios propios que requiere todo proceso participativo, al final, si el servicio funciona adecuadamente, la población acepta el sistema con un elevado grado de satisfacción; así lo corroboran los resultados de las encuestas allá donde se han realizado". Hay que tener en cuenta, además, que experiencias como el plebiscito organizado en Usurbil (Guipuzcoa) son concluyentes. La ciudadanía se decantó mayoritariamente por PaP, eso sí, después de un año de funcionamiento. La población cuenta con pautas y costumbres difícilmente cambiables; sin embargo, con buena y abundante información, los cambios son admitidos, sobre todo si, como es el caso, redundan en mayores niveles de reciclaje, en general, y mejores condiciones para la salud y el medio ambiente. A día de hoy es la única consulta popular organizada en Guipuzcoa y su implementación ha dado lugar a un 84\% de recogida selectiva de los RSU (datos de 2014).

Teniendo estas cuestiones previas en cuenta, a continuación se abordan los resultados y conclusiones del análisis.

\section{RESULTADOS Y DISCUSIÓN}

\section{V.1. Análisis comparativo de los sistemas de tratamiento basado en la metodología del análisis del ciclo de vida}

A continuación se muestran y analizan los resultados de seis simulaciones de los dos modelos de tratamiento considerados. Estas simulaciones se apoyan en una cuantificación numérica que pretende ser lo más exacta y ajustada a la realidad, pero no exenta de simplificaciones y aproximaciones, que han tratado de ser puntualmente señaladas. Por ello, estas simulaciones no pretenden caracterizar exactamente cada uno de los modelos de gestión y tratamiento, sino responder de forma cualitativa a las preguntas: ¿qué sistema de gestión y tratamiento de residuos es más caro?; ¿qué sistema genera más impactos ambientales y de salud?; ¿qué sistema genera más vertido a vertedero o a depósitos controlados?; ¿qué sistema valoriza más materia y energía? En definitiva, ¿cuál de los modelos es más eficiente y sostenible?

A continuación se describen someramente los seis escenarios analizados, cuyos resultados agregados más destacados son recogidos en la tabla adjunta. 


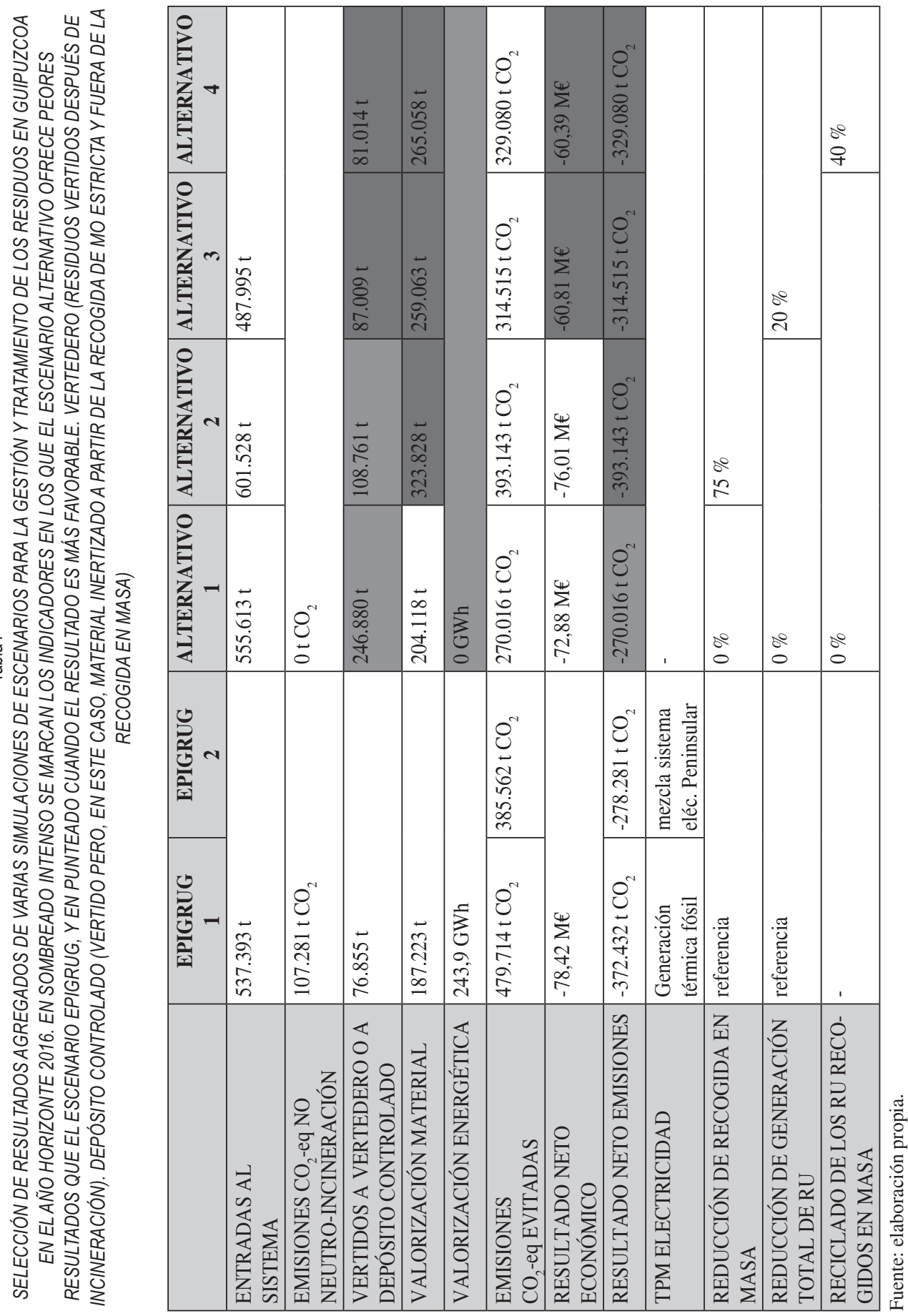


Los escenarios EPIGRUG 1 y EPIGRUG 2 modelan el sistema de gestión y tratamiento de residuos propuesto por el PIGRUG para el año 2016, con un flujo total de RSU de casi 540.000 toneladas anuales y unos porcentajes de reciclaje de menos del $30 \%$. Un flujo importante se deriva a la incineradora con valorización energética (cercano al 45\%), dando lugar a unas emisiones superiores a 100.000 toneladas de $\mathrm{CO}_{2}$, y generando $244 \mathrm{GWh}$ de electricidad. El sistema genera unos vertidos de residuos secundarios de casi 77.000 toneladas. Nuestro modelo arroja un balance económico a este sistema de tratamiento de $78 \mathrm{M€}$ anuales. Este dato no incluye diversos costes e ingresos pero que al ser del mismo orden en el resto de escenarios nos permite derivar conclusiones económicas en términos comparativos. En estos escenarios, una parte importante de los ingresos (más de $18 \mathrm{M€}$ ) proviene de la venta de la electricidad generada. La única diferencia entre estos dos escenarios radica en el tipo de generación considerado para la tecnología de producción marginal de electricidad. Estos dos escenarios sirven para desenmascarar una estrategia habitual en otros trabajos que pretenden minimizar los impactos ambientales de la incineración de residuos suponiendo (por lo general no de forma explícita) que la electricidad generada en los escenarios sin incineración se genera en centrales altamente contaminantes (centrales termoeléctricas con base en el carbón, generalmente hullas).

El escenario ALTERNATIVO 1 muestra los resultados de un sistema que, trabajando con los mismos flujos de residuos recogidos fundamentalmente en masa, de EPIGRUG, mantiene las mismas tasas de recogida selectiva, y por tanto todos los residuos que de otra forma se derivarían a la incineradora, en este escenario se ven derivados al vertedero. De esta manera, el depósito resulta más que triplicado (de 77 kt a 247 kt), y las emisiones netas de $\mathrm{CO}_{2}$ ofrecen un peor resultado que en EPIGRUG. Este escenario no es una alternativa viable ni deseable al diseño recogido en el DdP, pero tampoco desarrolla en absoluto toda la potencialidad de la valorización material que ofrece la implantación masiva de sistemas de recogida muy selectiva, que es analizada en los siguientes escenarios. Este escenario es el argumentado por los defensores a ultranza de la incineradora para el THG.

El escenario ALTERNATIVO 2 asume que la implantación masiva de exigentes sistemas de recogida selectiva como el PaP, permitiría reducir el flujo de residuos recogidos en masa en un 75\%, en línea con el objetivo marcado para el año 2020 por la EEDdP 2008-2016. Bajo estas condiciones la valorización material aumentaría hasta más de 320.000 toneladas anuales, y reduciría el flujo de residuos decantados en depósitos controlados (concepto acuñado en el EDDdP para indicar que el vertido no se realizaría en vertederos convencionales puesto que, al ser la MO recogida selectivamente, el resto aparecería inerte y podría utilizarse para rehabilitación de impactos paisajísticos: canteras, taludes, etc.), aunque se mantendría todavía por encima de la cantidad vertida en el escenario con incineración. También mejoraría el balance de emisiones de $\mathrm{CO}_{2}$, fundamentalmente debido a las importantes bonificaciones asociadas al consumo de energía en la fabricación de los materiales sustituidos por los materiales ahora reciclados, y que en el escenario EPIGRUG serían incinerados. Desde el punto de vista económico este escenario ALTERNATIVO 2 no supone una mejora con respecto a los anteriores ya analizados. Es ligeramente mejor que los EPIGRUG y ligeramente peor que el Alternativo 1, ya que la implantación masiva de sistemas de recogida muy selectiva implica mayores costes de recogida que en sistemas apoyados fundamentalmente en la recogida en masa. 
El escenario ALTERNATIVO 3, al asumir la implantación de un sistema de recogida selectiva PaP, basado en las experiencias en marcha, asume una disminución del flujo de residuos urbanos en términos absolutos del 20\% de la generación de RSU con respecto a los flujos generados en el escenario EPIGRUG. Este porcentaje responde a los datos obtenidos a partir de las fuentes bibliográficas y documentales consultadas en aquellos lugares con años de experiencia en la recogida selectiva a ultranza. De esta forma se reduce significativamente el flujo de residuos decantados en depósitos controlados (más de 20.000 toneladas menos que en el escenario anterior). También se reduce el volumen de valorización material, pero se sigue manteniendo por encima de lo valorizado en el escenario EPIGRUG. La reducción de la cantidad de residuos generados también reduce significativamente los costes de recogida. Globalmente, el escenario ALTERNATIVO 3 ya resulta significativamente más barato que el tomado como referencia y basado en el DdP con una incineradora a cola del sistema.

El escenario ALTERNATIVO 4 es la última variante del escenario ALTERNATIVO, y en él se añade una segunda unidad de reciclaje destinada específicamente a recuperar el máximo de materiales recuperables de entre los residuos que se siguen recogiendo en masa (el $25 \%$ restante de lo que en el escenario EPIGRUG se recogía en masa), y suponiendo una tasa de reciclado del $40 \%$ de las fracciones recuperables.

De esta forma y, a partir del análisis pormenorizado y basado en la metodología del ACV, se pueden deducir una serie de aseveraciones que, a continuación, sometemos a discusión. Se ha comprobado que el comportamiento de los escenarios ALTERNATIVOS son especialmente sensibles al porcentaje de recogida selectiva de los residuos generados, así como al volumen total de residuos generados. Si el sistema de gestión y tratamiento de residuos, al tiempo que prescinde de la incineración como método finalista de eliminación, establece ambiciosos métodos de recogida selectiva de materiales recuperables y de la fracción orgánica, esta estrategia puede dar lugar, perfectamente, a escenarios en los que la reducción en términos absolutos de residuos generados — con la ayuda de programas de información y concienciación de la población-, por un lado, y el aumento del flujo valorizado de materiales, por otro, supongan una ventaja comparativa en los principales indicadores de impacto ambiental, e incluso en términos económicos. Esta situación podría ser la reflejada por el escenario ALTERNATIVO 4 de este estudio, que proporciona mejores resultados comparativos en el aspecto económico (coste de 60,4 M€ frente a 78,4 M€ en el escenario EPIGRUG, sin incluir además otros costes socio-ambientales de la incineración). También proporciona mejores resultados en el ámbito de la valorización material (265kt de materiales valorizados, frente a $187 \mathrm{kt}$ en el escenario EPIGRUG). Este escenario ALTERNATIVO 4 presupone unos parámetros del sistema de gestión y tratamiento de los residuos que, además de ser realizables, pueden incluso ser mejorados con una adecuada política de concienciación social: el $75 \%$ de los residuos recogidos en masa pasan a ser recogidos de forma selectiva, por ejemplo mediante el PaP; se logra una reducción en términos absolutos del $20 \%$ de la generación de residuos; los residuos que se siguen recogiendo en masa se derivan a una planta de reciclaje que recupera el $40 \%$ del material reciclable, y el rechazo es inertizado previa decantación en depósito controlado. Dicha inertización responde a la reducción total de las reacciones que el resto de materia orgánica existente en dichos rechazos podría provocar.

El escenario ALTERNATIVO 4 no realiza valorización energética directa de los residuos a través de la generación de electricidad. Esto se debe a que los residuos se valorizan de 
forma directa materialmente, mediante el reciclado. No debemos olvidar que, tal y como establece la jerarquía de residuos, la valorización energética se sitúa jerárquicamente por debajo de las valorizaciones materiales, como es el caso del reciclado de materiales. La valorización material es cualitativamente superior a la exclusivamente energética, y además incluye de forma implícita un importante ahorro energético. Esto queda reflejado en nuestros escenarios en el hecho de que el balance neto de emisiones de $\mathrm{CO}_{2}$, en el escenario ALTERNATIVO 4 sea más beneficioso que el del escenario EPIGRUG1.

También debemos señalar que la valorización material del escenario ALTERNATIVO (en cualquiera de sus variantes, pero fundamentalmente en el 3 y 4) no se limita al reciclado de materiales. Gracias a las políticas de prevención y de reutilización de los materiales este escenario asume una reducción de los flujos de residuos entrantes al sistema de tratamiento y gestión del 20\%, suponiendo una importante valorización de materiales que se mantiene oculta al sistema, pero no por ello es inexistente.

En lo que respecta a la eliminación de los residuos secundarios generados, los dos sistemas considerados presentan flujos similares, en torno a $80 \mathrm{kt}$ anuales, pero con características cualitativamente muy diferentes. Mientras que el escenario ALTERNATIVO 4 decanta en depósito controlado el residuo inertizado (14 kt de rechazo en compostaje y 67 kt de rechazo de reciclaje), el escenario EPIGRUG debe gestionar el vertido o tratamiento de casi 4 kt de lixiviados generados en la incineración, más de 58 kt de escorias, y casi 14 kt de cenizas de incineración, un residuo que tiene la etiqueta de muy peligroso. Lo que es más grave, mientras que en los escenarios ALTERNATIVOS 3 y 4 es factible y deseable reducir el depósito controlado, en el escenario EPIGRUG esta reducción exigiría la reducción del nivel de actividad de la planta incineradora, lo que implicaría el aumento de los costes totales.

En lo que respecta a las repercusiones socioeconómicas: mientras los escenarios EPIGRUG concentran el grueso del gasto en la inversión y mantenimiento de la planta incineradora, reduciéndose considerablemente la necesidad de mano de obra a un computo en gasto del $11 \%$, los escenarios alternativos centran su mayor gasto en la mano de obra necesaria para la recogida a ultranza y la separación máxima a la vez que el compostaje o la biometanización de la Fracción Orgánica Compostable (FOC) (hasta más del 55\%).

Por último, debemos subrayar que diversas aproximaciones y simplificaciones realizadas penalizan el resultado del escenario ALTERNATIVO 3 y 4 frente al escenario EPIGRUG. En este sentido habría que denunciar la asignación de precio nulo a la venta del compost, que tampoco se considera sumidero de carbono. Al contrario, en el PIGRUG+DdP se ha supuesto una eficiencia energética en la planta de incineración $(25,1 \%)$ claramente sobredimensionada, pero imprescindible para tener acceso a las primas del régimen especial; se ha asignado el mismo coste económico a todos los residuos destinados a vertedero o depósito controlado; no se han considerado los impactos socio-ambientales de las emisiones al aire en la incineración, al margen de las emisiones de $\mathrm{CO}_{2}$, siendo estas emisiones inexistentes en los escenarios alternativos.

Todo esto nos lleva a concluir que parece perfectamente alcanzable un escenario de gestión y tratamiento de residuos urbanos para el territorio de Guipúzcoa que, sin recurrir a la incineración de los residuos como tratamiento finalista, logre un balance global en los ámbitos económico, material, energético y ambiental más favorable que el diseño propuesto en el DdP del PIGRUG (2008). Este escenario alternativo a la incineración requiere desarrollar 
al máximo las estrategias de recogida selectiva de los residuos generados, al tiempo que se logra reducir el flujo total de generación de residuos. La valorización material de los residuos se basaría en el compostaje de la FOC, que al recogerse de forma muy selectiva daría lugar a compost de muy alta calidad, y en la reutilización y el reciclaje de materiales, cuya recogida selectiva también permitiría reducir los rechazos generados en el reciclado. Todos estos elementos centrales del escenario alternativo están claramente alineados con la estricta aplicación de la jerarquía de residuos establecida por la DR de la UE.

La valorización energética de residuos en la incineradora del Centro de Gestión de Residuos de Guipuzcoa (CGRG) cuya principal infraestructura es la planta incineradora, aun sin construir debido al parón de estos años en lo que respecta al desarrollo del PIGRUG+DdP, es el elemento central del modelo de gestión propuesto por el PIGRUG. A continuación $\mathrm{y}$, de forma sucinta, sin embargo, demostramos que el modelo de valorización energética propuesto para el CGRG presenta importantes debilidades. El modelo de incineración del PIGRUG no supera los estándares de valorización energética requeridos por la Directiva de Residuos para que este modelo de incineración supere el estatus D10 (eliminación de residuos mediante incineración en tierra, y equiparable al vertido a vertedero) y alcance el estatus R1, de incineración con valorización energética (anexos I y II de la Directiva 2008/98).

El modelo de valorización energética del PIGRUG no es la referencia en los países europeos líderes en reciclaje, ya que se basa de forma exclusiva en la generación de electricidad. El modelo de valorización energética más extendido en el centro y norte de Europa, por el contrario, es el que valoriza la energía de los residuos de forma combinada proporcionando electricidad, vapor en condiciones de alta presión y temperatura, o calor. Según los últimos datos accesibles, en Dinamarca, por ejemplo, de 32 plantas incineradoras con información disponible, ninguna producía exclusivamente electricidad; en Alemania tan solo una planta de 56; en Austria una de once; en Noruega ninguna de doce. El modelo de valorización del PIGRUG no sigue, por tanto, la referencia del centro y norte de Europa, que es la generación combinada de calor, vapor y electricidad, esta última en menor proporción.

Múltiples elementos apuntan a que es prácticamente imposible que el CGRG cumpla con el requisito de eficiencia energética exigido por la directiva de residuos (DR) para que la planta ascienda del estatus D10 al R1. Estos problemas son reconocidos en público por diversas personalidades del sector con las que se ha llegado a tener entrevistas o conversaciones telefónicas: Alfonso Maíllo Sánchez, Asesor Técnico de Urbaser S.A.; Ella Stengler, gerente de CEWEP; D. Reimann, autor de la fórmula R1, recogida en la DR, y que determina el cumplimiento de valorización energética mínima; Xavier Elías, Director de la Bolsa de Subproductos de Cataluña; incluso los autores del informe Análisis de los sistemas de aprovechamiento de la fracción resto de residuos urbanos (ISR, 2008). Estos problemas se deben, fundamentalmente, al hecho de que si la energía térmica de los residuos se aprovecha solo para generar electricidad el sistema tiene que ser mucho más eficiente para cumplir con la directiva, ya que las pérdidas "estructurales" —el calor residual— en la generación eléctrica son más importantes que si se puede aprovechar directamente la energía de los residuos también en forma de calor.

Dados estos problemas para cumplir con la directiva, el proyecto de la planta de valorización energética (PVE) del PIGRUG incluye errores y omisiones que, corregidos, demuestran que la planta no cumpliría con el requisito R1 de la DR. Estos errores incluyen la omisión 
del cómputo, tanto de la electricidad importada necesaria para que funcione la planta, como de los combustibles suplementarios requeridos por la incineración, al realizar el cálculo de la eficiencia R1. El proyecto también supone una eficiencia termodinámica del ciclo de generación $(25,1 \%)$ muy superior a la real acreditada en otras plantas de características similares y recogidas en la documentación europea de referencia de incineración de residuos (BREF-WI). Además, debemos subrayar que el cumplimiento de los requisitos de eficiencia impuestos por la DR a las plantas incineradoras deben verificarse considerando valores de producción y consumo de energía durante periodos anuales completos de funcionamiento real de la planta, y de ninguna forma valores teóricos o de diseño. El proyecto del PIGRUG tampoco cumple con las recomendaciones MTD del BREF-WI referentes al aprovechamiento del calor generado en la incineración, e incluso escamotea una supuesta valorización energética de los residuos en forma de calor a través de un sistema de cogeneración alimentado con gas natural.

Si la incineradora del PIGRUG no cumpliera con el requisito R1 exigido por la DR para ascender de la categoría D10 a la R1 la planta incineradora no podría acreditar que la generación eléctrica se realiza con valorización energética, y por tanto no podría beneficiarse de las primas del régimen especial (RD 661/2007, apartado c.1), con una prima en 2011 de 59,63 €/MWh en tarifa regulada, o alternativamente de 30,581 €/MWh más el precio de mercado, que en 2010 fue de media en torno a $45 € / M W h$. Es de suponer que sin estas primas sus ingresos económicos por la venta de la electricidad en el mercado quedarían severamente reducidos, y por tanto gravemente dañada la viabilidad económica de la planta.

Al margen de los límites de eficiencia de la planta incineradora, también debemos subrayar que una fracción importante de la electricidad generada en la incineradora tendría la consideración de no renovable, ya que según la directiva europea de fomento de las energías renovables solo tendría esa consideración la proporción correspondiente a la fracción biodegradable de los RSU incinerados. Según nuestras estimaciones, al menos un tercio de la electricidad generada en la incineradora tendría la consideración de no renovable. También por esta misma razón, la planta incineradora presentaría unos niveles de emisión de $\mathrm{CO}_{2}$ por la electricidad generada muy superiores a los de la mezcla de la red eléctrica peninsular (600 g CO $2 / \mathrm{kWh}$, suponiendo un rendimiento del 25\% seguramente sobreestimado, frente a los $274 \mathrm{~g} \mathrm{CO}_{2} / \mathrm{kWh}$ del sistema eléctrico en 2011). Si entrara en funcionamiento, la incineradora del PIGRUG empeoraría el nivel de emisiones de la mezcla eléctrica del sistema eléctrico peninsular.

Por otra parte, partiendo de los marcos planificadores que para Guipúzcoa se han realizado (por una parte PIGRUG+DdP y por otra la EDDdP 2008-2016), la diferencia general entre los modelos expuestos, radica en la existencia o no de una gran infraestructura como es la incineradora. Todo ello y tal y como se demuestra fehacientemente, a su vez, condiciona el conjunto de las distintas medidas, pasos, etc.

\section{V.2. Análisis comparativo de las sustancias emitidas y su impacto sobre la salud y el medio ambiente}

La mayor parte de las veces, dentro de las planificaciones o la toma de decisiones político-administrativas, no se evalúan convenientemente los problemas que éstas puedan ejercer sobre la salud de las poblaciones y el medio ambiente. Ante las dificultades de valorar dichas 
cuestiones, se otorga un nombre muy significativo a estos impactos negativos: Externalidades. No obstante, esto no quiere decir que, como se ha hecho anteriormente a través del ACV, no se deba hacer un esfuerzo e intentar, aunque sea de forma aproximada, realizar un análisis de las evidencias contrastadas y admitidas por la comunidad científica mundial en estas cuestiones.

En el extenso barrido de información realizado para el análisis de esta cuestión destaca, sobre manera, la cantidad de bibliografía que sobre los impactos de la incineración existe a día de hoy.

También es de sobra conocido y ya han sido referenciados científicamente, los problemas que los vertederos sin recogidas selectivas o con un porcentaje alto de recogida en masa dan lugar sobre el medio ambiente; lixiviados, olores, plagas urbanas, emanación de diferentes gases, efecto invernadero de esos gases (Alia et al., 1992; Morris, 1996; Mwiganga y Kansiime, 2005).

En cualquier caso, cuanto mayor sea la selección de los residuos y, por tanto la recogida selectiva, mayor reducción de ciertos residuos se dará, mejores resultados de reciclaje y compostaje y, por tanto, menores cantidades a eliminar y menores efectos de esos residuos a eliminar sobre la salud humana y el medio ambiente.

Por otra parte y, tal y como se ha comprobado a lo largo de la investigación y del presente trabajo, es falso que una incineradora desestime la existencia de vertederos para recoger, en parte, aquellos residuos secundarios o derivados de los procesos de incineración; escorias y cenizas, entre otros. Éstos además, presentan un gran nivel de peligrosidad, sobre la salud y el medio ambiente, tal y como queda demostrado en la abundante bibliografía analizada y que, ahora se desarrolla y recoge de forma sintética.

A grandes rasgos una incineradora genera tres fracciones que pueden ser definidas, según los autores, como residuos secundarios o emisiones: cenizas, escorias y gases emitidos por la chimenea. Las dos primeras son residuos tóxicos con contenidos muy altos en dioxinas y metales pesados que deben llevarse a vertederos tóxicos, que a la larga serán contaminantes (Allsopp, Costner y Johnston, 2001). En cuanto a las últimas, las emisiones gaseosas, se pueden distinguir las siguientes sustancias:

\section{V.2.1. Partículas y micropartículas}

Es un campo de relativamente reciente descubrimiento y cuenta con una gran efervescencia investigadora. Está documentado un incremento del 1\% de la mortalidad por cada aumento de $10 \mu \mathrm{g} / \mathrm{m}^{3}$ en las micropartículas inferiores a $10 \mu \mathrm{g}$ (Ortega et al, 2001). Las partículas más finas, "respirables", en particular aquellas con un tamaño menor de $0.1 \mu \mathrm{m}$, denominadas ultrafinas, resultan lesivas para la salud humana, y se relacionan con enfermedades del aparato respiratorio como asma e incremento de mortalidad prematura por enfermedades respiratorias y cardíacas. Además, esta materia particulada cuenta con otra característica fundamental; son capaces de asociarse con moléculas como dioxinas, hidrocarburos policíclicos aromáticos, ácido clorhídrico, llevándolas hasta el alveolo, de manera que se ha demostrado que tienen capacidad cancerígena (Pope et al, 2002 y 2007), y últimamente mutagénica y heredable en animales de experimentación (Samet, DeMarini y Malling, 2004). Esto ya se había probado y así ha sido comunicado en diversos trabajos sobre vegetales cercanos a una planta incineradora (Ferreira et al 2000 y 2010). 


\section{V.2.2. Gases atmosféricos: Óxidos de nitrógeno}

El óxido nítrico (NO), que es el mayoritariamente liberado por las incineradoras, se oxida rápidamente a nitroso $\left(\mathrm{N}_{2} \mathrm{O}\right)$ o dióxido $\left(\mathrm{NO}_{2}\right)$, que es el responsable de su toxicidad: directamente cuando es inhalado, por toxicidad directa sobre el sistema respiratorio (De Fre y Wevers, 1998); e indirectamente mediante la formación fotoquímica del ozono troposférico, contaminante secundario con efectos respiratorios más graves que el mismo $\mathrm{NO}_{2}$ (Reinmann, Rentschler y Becker, 2001). Puede producir diversas patologías, dependiendo de su concentración: edema pulmonar, neumonía, bronquiolitis obliterante, enfisema (Ortega et al, 2001). Los óxidos de nitrógeno tienen una vida corta y se oxidan rápidamente a $\mathrm{NO}_{3}$ en forma de aerosol o bien a ácido nítrico $\left(\mathrm{HNO}_{3}\right)$. Tienen una gran trascendencia en la formación del llamado smog fotoquímico, del nitrato de peroxiacetilo (PAN) e influye así mismo en las reacciones de formación y destrucción del ozono troposférico y estratosférico, así como en el fenómeno de la lluvia ácida.

\section{V.2.3. Monóxido de carbono (CO)}

Produce envenenamiento a dosis altas por formación de carboxihemoglobina, pero por su rápida dispersión en la atmósfera, en las incineradoras no constituye un problema de salud pública tan importante como el de los restantes contaminantes. No obstante, es otro de los gases de efecto invernadero. Las incineradoras de residuos cuentan con importantes cantidades de emisión de este gas.

\section{V.2.4. Aerosoles ácidos}

Englobados en las micropartículas, básicamente el $\mathrm{SO}_{4} \mathrm{H}_{2}$ derivado del $\mathrm{SO}_{2}$, en niños se asocian directamente con efectos adversos sobre el aparato respiratorio (Ortega et al, 2001). En gran medida, este es el componente de mayor relevancia dentro de los procesos de lluvias ácidas que cuentan con graves impactos sobre la vegetación y los suelos de aquellos sectores entorno a fuentes de generación importantes.

\section{V.2.5. Anhídrido o dióxido carbónico $\left(\mathrm{CO}_{2}\right)$}

Se trata de uno de los gases que en mayor cantidad es emitido, en general, por cualquier tipo de actividad antrópica y, en particular, incluso por los procesos de respiración animal y vegetal. Se trata, así pues, del gas que más contribuye al efecto invernadero (Ortega et al, 2001; Meadows, Randers y Meadows, 2009). En general, su aumento se relaciona no sólo al incremento global de la temperatura, y con ello a múltiples afecciones ambientales (McNeill, 2002), sino también con abundantes afecciones sanitarias entre las que destaca un aumento general de la mortalidad.

El dióxido de carbono es considerado como el gas que mayor influencia tiene con respecto al calentamiento global. Queda demostrado que las incineradoras son una fuente de gran generación de este gas que, además, cuenta con una gran persistencia en la atmósfera, al contrario que el metano que se degrada con mayor facilidad aunque cuenta, a corto plazo, con una mayor capacidad de calentamiento atmosférico. 


\section{V.2.6. Metales}

Tanto en las emisiones gaseosas de una incineradora como en el resto de residuos secundarios existe una gran cantidad de metales, fundamentalmente pesados como cadmio, plomo, mercurio, cromo, arsénico o berilio. Los efectos adversos en la salud humana y el medio ambiente de las concentraciones emitidas por las chimeneas de las incineradoras son inciertos. Debido a la mejora en las tecnologías, los niveles de metales pesados que se liberan, a excepción del mercurio, han disminuido considerablemente en la última década. No obstante, su toxicidad es realmente preocupante, y como ocurre con las dioxinas, una reducción de los niveles de metales pesados en los gases de chimenea implica el correspondiente aumento de estos niveles en las cenizas, que en último término contaminarán el medio ambiente donde se depositen (Allsopp, Costner y Johnston 2001; WHO., 2010).

\section{V.2.7. Dioxinas, furanos y policlorobifenilos}

Los dos primeros muestran una estructura química formada por dos anillos aromáticos clorados o bromados, unidos por puentes oxígeno. Los últimos tienen una estructura similar, pero sin puentes oxígeno. Lo cierto es que no existen en la naturaleza, salvo en muy contadas ocasiones y a causa de accidentes o fenómenos puntuales y muy localizados como son grandes incendios forestales y erupciones volcánicas. Se forman en procesos de combustión por debajo de $800^{\circ} \mathrm{C}$. Se destruyen por encima de esa temperatura, pero al enfriarse se vuelven a sintetizar. Hay una gran cantidad de compuestos de cada clase, sólo algunos son tóxicos, pero en palabras de la Organización Mundial de la Salud: "las dioxinas son "delincuentes de repetición" para el medio ambiente. También se puede consultar en la página Web de dicha organización la frase que, a continuación, queda recogida: "En términos de emisión de dioxinas al medio, las incineradoras de residuos sólidos son los peores culpables (...) Las dioxinas no se eliminan fácilmente sino que provocan la contaminación del medio ambiente y las poblaciones humanas (...) Otras sustancias como los PCDDs y PCDFs, se ha demostrado que son también potentes promotores de tumores". Tanto las dioxinas como los furanos cuentan con la dudosa distinción de pertenecer al "club de la docena sucia", grupo especial de peligrosos productos químicos conocidos como contaminantes orgánicos persistentes (Thornton, 1993). La exposición a corto plazo de las personas a altos niveles de dioxinas puede degenerar en diferentes enfermedades. Basándose en datos epidemiológicos humanos, la dioxina (TCDD) fue categorizada por la IARC (Agencia Internacional para el Estudio del Cáncer) como carcinógeno humano conocido. Las dioxinas son productos no deseados de una amplia gama de procesos industriales. En términos de emisión de dioxinas al medio, las incineradoras de residuos sólidos son los peores culpables. Los fetos son los más sensibles a la exposición a dioxinas. Los recién nacidos pueden ser también más vulnerables a ciertos efectos (WHO. 1999). Otras dioxinas y furanos, como 1,2,3,7,8-PeCDD, 2,3,4,7,8-PeCDF y 1,2,3,4,6,7,8-HpCDD, se ha demostrado que son también potentes promotores de tumores» (WHO., 2000). Algunos estudios demuestran que la exposición a estas sustancias pueden acarrear un retraso de maduración autonómica del neonato, peor desarrollo cognitivo en la infancia y defectos de audición» (WHO. 2000 y 2011). Recientes trabajos confirman estos datos (Fierens et al, 
2003 y 2010). La OMS viene reduciendo desde 1990 la ingesta diaria tolerable (TDI), cuya última revisión fue establecida en $2,3 \mathrm{pg}$ TEQ/kg/d). Los ciudadanos del Estado español ingieren un promedio de estos compuestos superior a la ingesta diaria tolerable recomendada por la OMS (WHO., 1999 y 2000, Ortega et al., 2001; UK., 2002).

\section{V.2.8. Hidrocarburos policíclicos aromáticos}

Los benzopirenos, productos de la combustión del papel, son los principales responsables del cáncer de pulmón debido al tabaco. También producen alteraciones hematológicas (anemia aplásica) y dermatológicas. Con ellos se han observado los efectos mutagénicos antes citados (Ortega et al 2001).

\section{V.2.9. Productos desconocidos}

Son numerosos. Se estima que pueden ser tan tóxicos como los conocidos (USEPA., 2000). En este estudio se estima, además, que más de las tres cuartas del volumen de gases que es desalojado por una incineradora, seguramente respondan a compuestos químicos no descubiertos por la ciencia a día de hoy y cuya toxicidad, por lo tanto, nos es desconocida.

El Consejo Nacional de Investigación (NRC) 2000, institución de la Academia Nacional de Ciencias que se estableció para asesorar al gobierno de Estados Unidos, asevera lo siguiente: "Los contaminantes procedentes de una planta incineradora se dispersan en el aire, por lo que la población cercana a la planta se expone directamente por inhalación, o indirectamente al consumir comida o agua contaminada por las sustancias que se depositan en el suelo, la vegetación y el agua. Los efectos potenciales de metales y otros contaminantes persistentes en el medio ambiente, se extienden más allá del área donde se sitúa la incineradora". De esta manera, en el mismo informe, se estima que los efectos, según las condiciones atmosféricas pueden llegar más allá, incluso, de los 50 kilómetros.

Los contaminantes persistentes pueden transportarse a grandes distancias de la fuente de emisión y sufrir transformaciones físicas y químicas, pasando numerosas veces al suelo, al agua o a los alimentos (NRC., 2000). Este es el principal problema de estas sustancias de cara al medio ambiente y, cómo no, a la salud humana.

\section{CONCLUSIONES}

La UE, como consecuencia de la escasez que sufre de la mayor parte de las materias primas que consume, viene multiplicando la puesta en práctica de múltiples instrumentos para impulsar una economía circular: de impulso a la prevención (Directiva de ecodiseño, responsabilidad ampliada del productor-RAP); de impulso del reciclado y la reutilización (regulación administrativa: objetivos mínimos que deben alcanzar los Estados, RAP); instrumentos económicos (tasas proporcionales al volumen de residuos generados; impuestos a la incineración y vertido, que tienen en cuenta sus impactos ambientales y en la salud; subvenciones a la reutilización y reciclado).

Las anteriores consideraciones explican el elevado grado de reciclado y reutilización (70-80\%) de seis estados miembros: Alemania, Holanda, Bélgica (con políticas diferenciadas en Valonia y 
Flandes), Austria, Suecia y Dinamarca. Para conseguir dichas cotas han basado sus políticas en determinadas medidas: Reducción del volumen total de residuos, impuestos y/o prohibiciones en relación con el vertido y la incineración de residuos, pago por generación de residuos, políticas regulatorias, políticas fiscales, campañas de sensibilización y educación, entre otras.

Como consecuencia de un análisis comparado centrado en la metodología del ciclo de vida, se ha comprobado que el comportamiento de los escenarios ALTERNATIVOS son especialmente sensibles al porcentaje de recogida selectiva de los residuos generados, así como al volumen total de residuos generados. Si el sistema de gestión y tratamiento de residuos, al tiempo que prescinde de la incineración como método finalista de eliminación, establece ambiciosos métodos de recogida selectiva de materiales recuperables y de la fracción orgánica, esta estrategia puede dar lugar, perfectamente, a escenarios en los que la reducción en términos absolutos de residuos generados sea mayor y mejor. De la misma forma, los escenarios alternativos muestran mejores balances económicos y de emisión de gases de efecto invernadero.

Todo esto nos lleva a concluir que parece perfectamente alcanzable un escenario de gestión y tratamiento de residuos urbanos para el territorio de Guipúzcoa que, sin recurrir a la incineración de los residuos como tratamiento finalista, logre un balance global en los ámbitos económico, material, energético y ambiental más favorable que el diseño propuesto en el DdP del PIGRUG (2008).

A día de hoy y viendo las principales repercusiones que sobre la salud y el medio ambiente puede tener una incineradora, tal y como afirma Rowat (2000), resulta a todas luces desaconsejable la puesta en marcha de nuevas incineradoras, siendo totalmente necesaria la gradual desaparición de las ya existentes, al tiempo que se implementan todas las reglamentaciones que en materia de residuos existen a día de hoy y que profundizan en cuestiones como reducción, recogida selectiva, compostaje, biometanización, reutilización y reciclaje. Todo ello conllevará un incuestionable beneficio sobre el medio ambiente y la salud.

Muchas veces, dentro de las planificaciones que en materia de residuos existen y que, como el PIGRUG y su DdP, terminan con la propuesta de puesta en marcha de la incineradora, se citan cuestiones como que la tecnología será de última generación, estará sometida a la legislación vigente y contará con los filtros y medidas de seguridad más exigentes. Sin embargo, tal y como se demuestra en este trabajo y en la abundante y contrastada bibliografía, en cualquier caso y durante la evolución de la tecnología aplicada a la incineración se han dado casos evidentes de afectación sobre el medio ambiente y la salud humana. Además, han existido múltiples contingencias, accidentes y problemas donde se ha demostrado que se estaba vertiendo a la atmósfera por encima de lo reglamentado (Beçanson, Valdemingomez, Cumbria, Palma de Mallorca, etc.).

Las incineradoras generan residuos de tipo sólido y gaseoso principalmente, los cuales entran en contacto con el medio ambiente, siendo fuentes de contaminación y generación de enfermedades en los seres humanos y graves impactos sobre el medio ambiente (Elliot et al., 1996; Ramos et al., 1997; Osius y Karmaus, 1998; Osius et al., 1999; Elliot et al., 2000; Knox, 2000; Ten Tusscher, Stam y Koppe, 2000; Viel et al. 2000; De Baere y De Leeuw, 2001; Nouwen et al. 2001; Schuhmacher, 2001; Staessen et al., 2001; Ma, 2002; 
Comba et al. 2003; Dummer, Dickinson y Parker, 2003; Floret et al., 2003; Hours et al., 2003; Cordier et al., 2004; Franchini et al., 2004; Saintot, 2004; Evans, 2006; Ferreira et al., 2010; WHO, 2000 y 2011).

Las enfermedades desarrolladas a partir del material emitido por las incineradoras se pueden producir a través de su ingesta por medio de una compleja cadena generada a través de la contaminación del ganado y los cultivos, siendo además, una fuente desaceleradora de la economía agraria, ya que disminuye su rendimiento y calidad.

La incineración necesita de una cantidad creciente y permanente de residuos, lo cual entorpece las labores de reciclaje y la convierte en una solución poco sostenible, a pesar de la generación de energía. Asimismo, también genera numerosos residuos que de igual manera deben ser eliminados, los cuales son altamente tóxicos y nocivos para la salud humana.

Cualquier análisis sobre los métodos de tratamiento de residuos, ya sean de tipo domiciliario, biosanitarios o industriales, merecen un exhaustivo trabajo que considere todas las dimensiones de la realidad que pueden verse afectadas, tal es la calidad de vida humana, una alteración de los sistemas territoriales, impactos negativos en el medio ambiente y consecuencias de tipo social y cultural.

\section{BIBLIOGRAFÍA}

AD-HOC WORKING GROUP. (2010): Critical raw materials for the EU. European Commission.

ALIA, M.; PASTOR, J.; GIL, A.; URCELAY, A. y ANTÓN, F.A. (1992): «Comparative study of toxicity of leachates from three urban landfill sites over different parent materials». Toxicology letters, supplement 1992, 275-276.

ALLSOPP, M., COSTNER P. y JOHNSTON P. (2001): «Incineration and human health. State of knowledge of the impacts of waste incinerators on human health». Environmental science and pollution research international, 8 (2): 141-145.

ASTRUP, T. (2007): «Pretreatment and utilization of waste incineration bottom ashes: Danish experiences». Waste Management, 27 (10):1452-1457.

COLOMER, J. (Coor.) (2010): Manual de recogida selectiva puerta a puerta, Associació de Municipis Catalans per a recollida selectiva porta a porta.

COMBA, P., ASCOLI, V., BELLI, S., BENEDETTI, M., GATTI, L., RICCI, P. y TIEGHI, A. (2003): «Risk of soft tissue sarcomas and residence in the neighbourhood of an incinerator of industrial wastes». Journal of Occupational and Environmental Medicine, 60 (9): 680-683.

COMISIÓN EUROPEA. (2006): Integrated Pollution Prevention and Control, Reference Document on the Best Available Techniques for Waste Incineration (BREF-WI). Agosto.

COMISIÓN EUROPEA. (2008): The Raw Materials Initiative-Meeting our critical needs for growth and jobs in Europe, $\operatorname{COM}(2008) 699$

COMISIÓN EUROPEA. (2010): Próximas medidas de gestión de biorresiduos en la Unión Europea, $\mathrm{COM}(2010) 235$ final

COMISIÓN EUROPEA. (2010): Estrategia 2020 para un crecimiento inteligente, sostenible e integrador, $\mathrm{COM}(2010) 2020$ final 
COMISIÓN EUROPEA. (2011): Informe temático para la prevención y el reciclado de residuos, COM(2001) 13 final.

COMISIÓN EUROPEA. (2011): Hoja de Ruta hacia una Europa eficiente en el uso de recursos, $\mathrm{COM(2010)} 2020$ final.

COMISIÓN EUROPEA. (2011): Guidelines on the interpretation of the R1 energy efficiency formula for incineration facilities dedicated to the processing of Municipal Solid Waste according to Annex II of Directive 2008/98/EC on Waste, R1-formula, junio 2011.

CORDIER, S., CHEVRIER, C, ROBERT-GNANSIA, E., LORENTE, C., BRULA, P. y HOURS, M. (2004): «Risk of congenital anomalies in the vicinity of municipal solid waste incinerators». Journal of Occupational and Environmental Medicine, 61 (1): 8-15.

CORONEOS, C.J. y NANAKI, E.A. (2012): Integrated solid waste management and energy production-a life cicle assessment approach: the case study of the city of Tessaloniki. Journal of Cleaner Production, 27: 141-150.

DE BAERE, F. y DE LEEUW, K. (2011): Report on the health impact of the MIWA-waste incinerator in Sint-Niklaas. Sint-Niklaas, Belgium.

DE FRE, R.. (2002): Dioxins and Dioxin-like PCBs in the UK Environment. Consultation Document. Department for Environment, Food and Rural Affairs. London.

DE FRE, R. y WEYERS, M. (1998): «Underestimation in dioxin inventories». Organohalogen Compounds, 36: 17-20.

DIEDEREN, A. (2010): Global Resource Depletion, Delft, Eburon.

DUMMER, TJ., DICKINSON, HO. y PARKER, L. (2003): «Adverse pregnancy outcomes around incinerators and crematoriums in Cumbria, north west England, 1956-93». Journal of Epidemiolgy and Community Health, 57 (6): 456-61.

ELÍAS, X. (2011): «La valorización energética frente a la Directiva Marco de Residuos 2008/98». ZEROWASTE, julio 2011.

ELLIOTT, P., SHADDICK, G., KLEINSCHMIDT, I., JOLLEY, D., WALLS, P., BERESFORD, J. y GRUNDY, C. (1996): "Cancer incidence near municipal solid waste incinerators in Great Britain». British Journal of Cancer, 73 (5): 702-710.

ELLIOTT, P, EATON, N., SHADDICK, G. y CARTER, R. (2000): «Cancer incidence near municipal solid waste incinerators in Great Britain. Part 2: histopathological and casenote review of primary liver cancer cases». British Journal of Cancer, 82 (5): 1103-1106.

ETC/SCP. (2012): Overview of use of landfill taxes in Europe. ETC/SCP: Recycling Rates of Metals, Paris, UNEP.

EVANS, N. (2006): «Evidencia. ¿Cuál es la conexión entre el Medio Ambiente y el Cancer de mama». Brest Cancer Found/Breast Cancer Action. San Francisco (EE UU) 2006.

FERREIRA, MI., PETRENKO, H., LOBO, DJ., RODRIGUES, GS., MOREIRA, A. y SALDIVA, PH. (2000): «In situ monitoring of the mutagenic effects of the gaseous emissions of a solid waste incinerator in metropolitan Sao Paulo, Brazil, using the Tradescantia stamen-hair assay». Journal of the Air \& Waste Management Association, 50 (10): 18521856.

FIERENS, S., MAIRESSE, H., HERMANS, C., BERNARD, A., EPPE, G., FOCANT, JF. y DE PAUW, E. (2003): «Dioxin accumulation in residents around incinerators». J Journal of Toxicology and Environmental Health, 66 (14): 1287-1293. 
FLORET, N., MAUNY, F., CHALLIER, B., ARVEUX, P., CAHN, JY. y VIEL, JF. (2003): «Dioxin emissions from a solid waste incinerator and risk of non-Hodgkin lymphoma». Epidemiology and Infection Journal, 14 (4): 392-398.

FRANCHINI, M., RIAL, M., BUIATTI, E. y BIANCHI, F. (2004): «Health effects of exposure to waste incinerator emissions: a review of epidemiological studies». Annalli dell' Istituto Superiori di Sanità , 40 (1): 101-115.

FUKUDA, Y., NAKAMURA, K. y TAKANO, T. (2003): «Dioxins released from incineration plants and mortality from major diseases: an analysis of statistical data by municipalities». Journal of Medical and Dental Sciences, 50 (4): 249-255.

HARVEY, LD. (2010): Energy and the New Reality 1: Energy Efficiency and the Demand for Energy Services. Earthscan, Londres.

HOURS, M., ANZIVINO-VIRICEL, L., MAITRE, A., PERDRIX, A., PERRODIN, Y., CHARBOTEL, B. y BERGERET, A. (2003): «Morbidity among municipal waste incinerator workers: a cross-sectional study». International Archives of Occupational Environmental Health, 76 (6): 467-472.

IHOBE (2009): Análisis del ciclo de vida y huella de carbono. <http://www. ihobe.net/Publicaciones/Ficha.aspx? IdMenu=750e07f4-11a4-40da-840c0590b91bc032\&Cod $=\{$ BC53A7DB-3EDB-4B96-AC9A-1F163ED0D76B $\}>$.

IPCC (2007): Bogner, J., M. Abdelrafie Ahmed, C. Diaz, A. Faaij, Q. Gao, S. Hashimoto, K. Mareckova, R. Pipatti, T. Zhang, Waste Management, In Climate Change 2007: Mitigation. Contribution of Working Group III to the Fourth Assessment Report of the Intergovernmental Panel on Climate Change, Cambridge University Press, Cambridge, United Kingdom and New York, NY, USA.

ISR. (2008): Análisis de los sistemas de aprovechamiento de la fracción resto de residuos urbanos. ISR.

KNOX, E. (2000): «Childhood cancers, birthplaces, incinerators and landfill sites». International Journal of Epidemiology, 29 (3): 391-397.

LOZANO, P.J. y LOZANO, M.A. (2008): «Las mancomunidades de servicios, un ejemplo de vertebración territorial para Guipúzcoa. Caracterización de los residuos domésticos en dicho territorio a partir de la gestión mancomunada». Boletín de la Asociación de Geógrafos Españoles, no 48: 155-174.

MAÍlLO, A. (2012): La Combustión de los residuos sólidos urbanos. Conferencia en el Comité de Energía y Recursos Naturales del Instituto de la Ingeniería de España, abril 2012,<www.upcomillas.es/catedras/crm/descargas/2011-2012/seminario\%20 18.04.2012-maillo.pdf $>$.

MA, HW., LAI, YL. Y CHAN, CC. (2002): «Transfer of dioxin risk between nine major municipal waste incinerators in Taiwan». Environmental science and pollution research international, 28 (1-2): 103-110.

MC NEILL, J.R. (2003): Algo nuevo bajo el sol. Historia medioambiental del mundo en el siglo XX. Alianza ensayo. Madrid.

MEADOWS, D. RANDERS, J. y MEADOWS, D. (2009): Los límites del crecimiento 30 años después. Galaxia Gutemberg/Círculo de lectores. Madrid. 
MICHELOZZI, P., FUSCO, D., FORASTIERE, F., ANCONA, C., DELL'ORCO, V. y PERUCCI, CA. (1998): «Small area study of mortality among people living near multiple sources of air pollution». Journal of Occupational and Environmental Medicine; 55: 611-615.

MWIGANGA, M. y KANSIIME, F. (2005): «The impact of Mpererwe landfill in KampalaUganda, on the surrounding environment». Physics and Chemistry of the Earth, vol. 30: 744-750.

MORRIS, J. (1996): «Recycling versus incineration: an energy conservation analysis». Journal of Hazardous Materials, 47 (1-3): 277-293.

NOUWEN, J., CORNELIS, C., DE FRE, R., WEVERS, M., VIAENE, P., MENSIK, C., PATYN, J., VERSCHAEVE, L., HOOGHE, R., MAES, A., COLLIER, M., SCHOETERS, G., VAN CLEUVENBERGEN, R. y GEUZENS, P. (2001): «Health risk assessment of dioxin emissions from municipal waste incinerators: the Neerlandquarter (Wilrijk, Belgium)». Chemosphere, 43 (4-7): 909-923.

OH, SM., RO, KS. y CHUNG, KH. (2003): «Induction of cytochrome P4501A and endocrine disrupting effects of school incinerator residues». Environmental Monitoring and Assessment, 83 (1): 35-45.

ÖKO-INSTITUT (2009): Critical Metals for Future Sustainable Technologies and their Recycling Potential, Öko-Institut.

ORTEGA, J.A., FERRÍS, J.I., TORTAJADA, J.A., LÓPEZ, J., GARCÍA, A., CÁNOVAS, O., BERBEL, A., ORTÍ, V., FERRÍS, B., BESELER, E. y E ANDREU, E. (2001): «El pediatra y la incineración de residuos sólidos. Conceptos básicos y efectos adversos en la salud humana». Revista Española de Pediatría: clínica e investigación, 57 (6): 473-490.

OSIUS, N. y KARMAUS, W. (1998): «Thyroid hormone level in children in the area of a toxic waste incinerator in South Essen». Gesundheitswesen, 60 (2): 107-12.

OSIUS, N., KARMAUS, W., KRUSE, H. y WITTEN J. (1999): «Exposure to polychlorinated biphenyls and 17evels of thyroid hormones in children». Environmental Health Perspectives, 107 (10): 843-849.

PARLAMENTO EUROPEO Y CONSEJO DE EUROPA (2008): Directiva 2008/98/CE del Parlamento Europeo y del Consejo de 19 de noviembre de 2008 sobre los residuos. UE.

PARLAMENTO EUROPEO Y CONSEJO DE EUROPA (2009): Directiva 2009/28/CE del Parlamento Europeo y del Consejo de 23 de abril de 2009 relativa al fomento del uso de energía procedente de fuentes renovables y por la que se modifican y se derogan las Directivas 2001/77/CE y 2003/30/CE.UE.

PUIG, I. (Coor.) (2010): La incineración de residuos en cifras, España.

RABL, A. (2008): «Environmental Impacts and Costs of Municipal Solid Waste». Waste Management and Research, 26 (2): 147-162.

RAMOS, L., ELJARRAT, E., HERNANDEZ, L.M., ALONSO, L., RIVERA J. y GONZÁLEZ, M.J. (1997): «Levels of PCDDs and PCDFs in farm cow's milk located near potential contaminant sources in Asturias (Spain). Comparison with levels found in control, rural farms and commercial pasteurized cow's milks». Chemosphere, 35 (10): 2167-79.

REE (Red Eléctrica de España) (2009): Boletines mensuales de Red Eléctrica de España, a partir de 2007.<http://www.ree.es/sistema_electrico/boletin_mensual_ree.asp >. 
REE (Red Eléctrica de España) (2012): Avance del informe 2011 del sistema eléctrico español.<http://www.ree.es/sistema_electrico/informeSEE.asp $>$.

REINMANN, J., RENTSCHLER, W. y BECKER, E. (2001): «New results and features of the continuous dioxin/furan monitoring system Amesa». Organohalogen Compounds , 50: 99-102.

REINMANN, J. (2002): «Results of one year continuous monitoring of the PCDD/PCDF emissions of waste incinerators in the Walloon region of Belgium with Amesa». Organohalogen Compounds Journal, 59: 77-80.

REIMANN, D. (2009): CEWEP Energy Report II (Status 2004-2007). Results of Specific Data for Energy, R1 Plant Efficiency factor and Net Calorific Value (NCV) of 231 European WtE Plants.

ROWAT, SC. (2000): «Incinerator toxic emissions: a brief summary of human health effects with a note on regulatory control». Medical Hypotheses, 52 (5): 389-96.

SAINTOT, M., MALAVEILLE, C., HAUTEFEUILLE, A. y GERBER, M. (2004): «Interaction between genetic polymorphism of cytochrome P450-1B1 and environmental pollutants in breast cancer risk». European Journal Cancer Prevention, 13 (1): 83-86.

SAMET, JM., DE MARINI, DM. y MALLING, HV. (2004): «Do Airborne Particles Induce Heritable Mutations? ». Science, 304 (5673): 971-972.

SCHUHMACHER, M., MENESES, M., XIFRO, A. y DOMINGO, JL. (2001): «The use of Monte-Carlo simulation techniques for risk assessment: study of a municipal waste incinerator». Chemosphere, 43 (4-7): 787-99.

STENGLER, E. (2010): On the Road to Recovery: Achieving R1 Status, WASTE management world. <http://www.waste-management-world.com/index/display/articledisplay/9759616578/articles/waste-management-world/volume-11/issue-6/features/ on-the-road-to-recovery-achieving-r1-status.html>.

TEN TUSSCHER, GW., STAM, GA. y KOPPE, JG. (2000): «Open chemical combustions resulting in a local increased incidence of orofacial clefts». Chemosphere, 40 (9-11): 1263-1270.

USEPA. (2000): «External peer review». Human health risk of waste combustion. P. 26. may 12.

VAN GERVEN, T., GEYSEN, D., STOFFELS, L., JASPERS, M., WAUTERS G. y VANDECASTEELE, C. (2005): «Management of incinerator residues in Flanders (Belgium) and in neighbouring countries. A comparison». Waste Management, 25 (1): 75-87.

VIEL, JF., ARVEUX, P., BAVEREL, J. y CAHN, JY. (2000): «Soft-tissue sarcoma and non-Hodgkin's lymphoma clusters around a municipal solid waste incinerator with high dioxin emission levels». American Journal of Epidemiology, 152 (1): 13-19.

VOINOV, A. (2008): Systems Science and Modeling for Ecological Economics. Academic Press, Londres.

WEIDEMA, B., FREES N, y NIELSEN, A. (1999): «Marginal production technologies for life cycle inventories». The International Journal of Life Cycle Assessment. Vol. 4 (1), 48-56.

WEIDEMA, B. (2000): «Avoiding Co-Product Allocation in Life-Cycle Assessment». Journal of Industrial Ecology, Volume 4 (3): 11-33. 
WORLD HEALTH ORGANIZATION. (1999): Fact sheet $N^{\circ} 225$. June 1999. Dioxins and their effects on human health.

WORLD HEALTH ORGANIZATION. (2000): Air Quality Guidelines-Second Edition. WHO Regional Office, Copenhagen, Denmark, 2000.

\section{AGRADECIMIENTOS}

El presente artículo ha sido posible gracias al proyecto de investigación: Del gobierno a la gobernanza y gobernabilidad efectiva del territorio: guías para un nuevo desarrollo territorial (GOBEFTER). CSO2012-36960. 